\title{
Molecularly imprinted solid-phase extraction and flow-injection chemiluminescence for trace analysis of 2,4-dichlorophenol in water samples
}

\author{
Qin-Zhong Feng $\cdot$ Li-Xia Zhao $\cdot$ Wei Yan $\cdot$ Feng Ji • \\ Yan-Lin Wei • Jin-Ming Lin
}

Received: 19 November 2007 / Revised: 23 February 2008 / Accepted: 5 March 2008 / Published online: 19 April 2008

(C) Springer-Verlag 2008

\begin{abstract}
Highly sensitive flow-injection chemiluminescence (CL) combined with molecularly imprinted solid-phase extraction (MISPE) has been used for determination of 2,4dichlorophenol (2,4-DCP) in water samples. The molecularly imprinted polymer (MIP) for 2,4-DCP was prepared by noncovalent molecular imprinting methods, using 4-vinylpyridine (4-VP) and ethylene glycol dimethacrylate (EGDMA) as the monomer and cross-linker, respectively. 2,4-DCP could be selectively adsorbed by the MIP and the adsorbed 2,4-DCP was determined by its enhancing effect on the weak chemiluminescence reaction between potassium permanganate and luminol. The enhanced CL intensity was linear in the range from $1 \times 10^{-7}$ to $2 \times 10^{-5} \mathrm{~g} \mathrm{~mL}^{-1}$. The $\operatorname{LOD}(S / N=3)$ was $1.8 \times 10^{-8} \mathrm{~g} \mathrm{~mL}^{-1}$, and the relative standard deviation (RSD) was $3.0 \%(n=11)$ for $1.4 \times 10^{-6} \mathrm{~g} \mathrm{~mL}^{-1}$. The proposed method had been successfully applied to the determination of 2,4-DCP in river water.
\end{abstract}

Keywords Molecularly imprinted polymer.

2, 4-Dichlorophenol · Flow chemiluminescence .

Molecularly imprinted solid-phase extraction

\section{Introduction}

2,4-Dichlorophenol (2,4-DCP) and other chlorophenols are among the most important industrial chemicals. 2,4-DCP is

Q.-Z. Feng $\cdot$ L.-X. Zhao $(\bowtie) \cdot$ W. Yan $\cdot$ F. Ji $\cdot$ Y.-L. Wei $\cdot$

J.-M. Lin $(\bowtie)$

State Key Laboratory of Environmental Chemistry and

Ecotoxicology, Research Center for Eco-Environmental Sciences,

Chinese Academy of Sciences,

P. O. Box 2871, Beijing 100085, China

e-mail: zlx@rcees.ac.cn

e-mail: jmlin@mail.rcees.ac.cn used extensively in wood preservatives, inhibitors in cooling towers, insecticides, fungicides, herbicides, and biocides in industrial and agricultural sectors throughout the world $[1,2]$. It has, however, recently been suspected of being an endocrine disrupter [3]. Notably, it is an environmental pollutant. Not only does inhalation of dust containing 2, 4-DCP irritate the respiratory tract but detrimental effects on the kidneys, liver, and blood-forming organs are known [4]. 2,4-DCP also can cause death, respiratory failure, bone marrow atrophy, and skin damage in animals and give a bad taste and odor to food and water [5,6]. The US EPA and State Environmental Protection Administration of China have included it as priority pollutant. Gao et al. [7] studied the levels and spatial distribution of chlorophenols in surface water in China. The results indicated that 2,4-dichlorophenol was more frequently detected at higher concentrations in the rivers of North China than in those of South China. Concentrations of 2,4-dichlorophenol ranged from $<1.1$ to $19,960.0 \mathrm{ng} \mathrm{L}^{-1}$, with a median level of 5.0ng $\mathrm{L}^{-1}$, and the $90 \%$ percentile value was $60.0 \mathrm{ng} \mathrm{L}^{-1}$. Therefore, it appears of great interest to design efficient and sensitive analytical methods which are able to detect trace levels of 2,4-DCP.

Although the methods of detection of 2,4-DCP, such as UV spectrophotometry [8], electrooxidation of 2,4-DCP on a rotating glassy carbon (GC) disk electrode [9], and highperformance liquid chromatography [10-13] have been developed, they have disadvantages such as low sensitivity, expensive instrumentation, or tedious operation. In order to improve the sensitivity, highly sensitive chemiluminescence (CL) detection, which has a low detection limit and wide linear dynamic range, and which uses relatively simple and inexpensive instrumentation, could be used [14, 15].

Chemiluminescence, the production of light from a chemical reaction, has proved to be a useful phenomenon in the laboratory, finding ever increasing applications in 
analytical chemistry [16], but it has poor selectivity. Sample pretreatment is therefore necessary before the determination. Solid-phase extraction (SPE) is routinely used to preconcentrate analytes of interest at low levels of concentration, but the complex matrixes may interfere with the separation efficiency. Nowadays, one of the most interesting objectives for analytical chemistry researchers is to improve the selectivity of the sorbents used in SPE, and molecularly imprinted polymers (MIP) are now being actively researched. The combination of MIPs and CL has been applied in medicine $[17,18]$.

The selectivity of MIP arises because the target analyte (template) is present in the polymerization mixture during synthesis of the MIP. Once the highly crosslinked polymer has formed, the template molecules are removed from the polymer matrix revealing selective binding sites in the polymer matrix. As a consequence of these binding sites (i.e. molecular recognition sites), the molecularly imprinted polymer is able to selectively recognize the template molecule among other components in a complex sample [19]. The molecularly imprinted polymer can be applied in solid phase extraction (MISPE) for purification of samples [2023]. Caro et al. [23] prepared three polymers using 4chlorophenol (4-CP) as the template, following different procedures (non-covalent and semi-covalent) and using different functional co-monomers - 4-vinylpyridine (4-VP) and methacrylic acid (MAA). The polymers were evaluated to check their selectivity as molecularly imprinted polymers (MIPs) in solid-phase extraction (SPE) coupled on-line to liquid chromatography. The MIP was used to selectively extract the 4-chloro-substituted compounds and 4-NP from river water samples. MISPE polymers have also been used as stationary phases for chromatographic separations [24], for molecular and ionic separations by selective sorption $[25,26]$, as recognition entities in sensors $[27,28]$, in immunoassays [29, 30], and as catalysts [31, 32].

In this work, 2,4-DCP was chosen as template, 4-VP as functional monomer, and EGDMA as the cross linking agent. A novel method combining MISPE with CL was used for selective preconcentration and analysis of 2,4-DCP from water samples. The method was validated and used to determine 2,4-DCP in river water, with satisfactory results.

\section{Experimental}

Reagents

The chemicals used for polymer synthesis (2,4-DCP, 4vinylpyridine (4-VP), and ethylene glycol dimethacrylate (EGDMA)), 2,4-dimethylphenol (2,4-DMP), 4-chlorophenol (4-CP), 2,6-dichlorophenol (2,6-DCP), and 2,4,6-trichlorophenol
(2,4,6-TCP) were all from Acros Organics. 2,2'-Azobisisobutyronitrile (AIBN) was from Shanghai No. 4 Reagent and H.V. Chemical Company (Shanghai, China) and acetonitrile was from J.T. Baker (USA). The monomers were purified by standard procedures to remove stabilizers. The AIBN was recrystallized from ethanol. Acetic acid and chloroform were purchased from Beijing Chemical Reagents Company (Beijing, China). Methanol and ethanol were from Beijing Bei Hua Finachemical Company (Beijing, China).

The chemicals for CL were at least of analytical grade and solutions were prepared with deionized ultrapure water (18.3M $\Omega \mathrm{cm}^{-1}$; EasyPure LF Barnstead, Iowa, USA). Potassium permanganate $\left(\mathrm{KMnO}_{4}\right)$, luminol, and $\mathrm{NaOH}$ were from Beijing Chemical Reagents Company. Stock solution of $\mathrm{KMnO}_{4}\left(0.001 \mathrm{~mol} \mathrm{~L}^{-1}\right)$ was prepared by dissolving $39.5 \mathrm{mg} \mathrm{KMnO}_{4}$ in $250 \mathrm{~mL}$ water and filtering through glass wool. It was stored in dark brown bottles. Stock solution of luminol $\left(0.025 \mathrm{~mol} \mathrm{~L}^{-1}\right)$ was prepared by dissolving $1.1073 \mathrm{~g}$ luminol in $250 \mathrm{~mL} 1 \mathrm{mmol} \mathrm{L}^{-1} \mathrm{NaOH}$ solution. Stock standard solution of 2,4-DCP $\left(500 \mathrm{mg} \mathrm{L}^{-1}\right)$ was prepared fresh weekly by dissolving $50 \mathrm{mg}$ in $100 \mathrm{~mL}$ water. It was stored at $4^{\circ} \mathrm{C}$ in a refrigerator. All working solutions were prepared by diluting the stock standard solutions to the concentrations required.

\section{Apparatus}

The flow-injection system (Lumflow LF-800, Japan) used in this work is shown in Fig. 1. A peristaltic pump (Changzhou, China) was used to deliver all solutions at the same flow rate- $1.2 \mathrm{~mL} \mathrm{~min}^{-1}$ for each line. CL signals were recorded and processed by a personal computer equipped with LUM-2000 data-processing program (Research Center for Eco-Environmental Sciences, Chinese Academy of Sciences, Beijing, China). To evaluate the polymers, ground polymer particles were suspended in water and the solutions were determined with the UV2101PC spectrophotometer (Shimadzu Corporation, Japan).

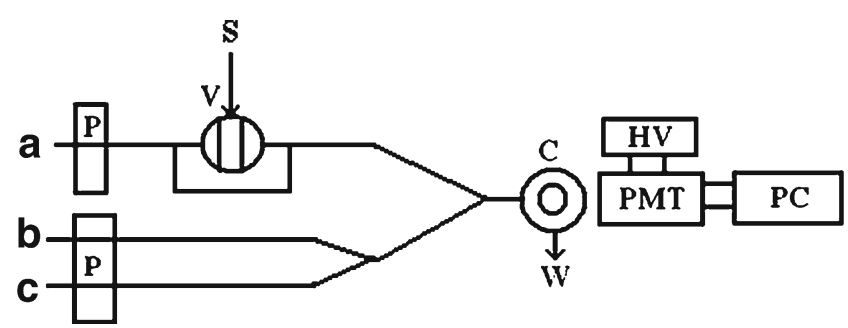

Fig. 1 CL System: $\mathrm{KMnO}_{4}-$ luminol $/ \mathrm{NaOH}$. a $\mathrm{H}_{2} \mathrm{O}$; b luminol/ $\mathrm{NaOH} ;$ c $\mathrm{KMnO}_{4} ; P$, peristaltic pump; $C, \mathrm{CL}$ flow cell; $S$, sample; $P M T$, photomultiplier; $P C$, personal computer; $W$, waste water; $V$, injection valve 
Preparation of 2,4-DCP-MIP and non-MIP

For preparation of the imprinted polymer, the template molecule, 2,4-DCP $(0.326 \mathrm{~g}, 2 \mathrm{mmol})$ was dissolved in $\mathrm{CHCl}_{3}(10 \mathrm{~mL})$ in a $25-\mathrm{mL}$ thick-walled glass tube and the functional monomer $4-\mathrm{VP}(0.850 \mathrm{~g}, 8 \mathrm{mmol})$, the cross linking agent EGDMA $(8.000 \mathrm{~g}, 40 \mathrm{mmol})$, and the initiator AIBN $(0.185 \mathrm{~g}, 1.12 \mathrm{mmol})$ were then added to the solution. The solution was cooled on an ice bath and purged with oxygen-free nitrogen for $10 \mathrm{~min}$. The glass tube was then sealed under nitrogen and placed in a water bath at $60^{\circ} \mathrm{C}$. The reaction was allowed to proceed for $24 \mathrm{~h}$. The resulting hard polymer was crushed and ground to furnish regularly sized particles between 30 and $38.5 \mu \mathrm{m}$ suitable for MISPE evaluation. A reference polymer (NIP) without 2,4-DCP was prepared by the same procedure. MIP particles were washed with methanol-acetic acid 90:10 $(v / v)$ by Soxhlet extraction. Finally, the particles were dried in a vacuum at $35^{\circ} \mathrm{C}$.

Preparation of the MISPE and the sample

MIP particles (300mg) were packed in an empty column and used for molecularly imprinted solid-phase extraction (MISPE). The MISPE cartridges were conditioned with $10 \mathrm{~mL}$ methanol then $10 \mathrm{~mL}$ water. A pure water sample was passed through the cartridge at $2-3 \mathrm{~mL} \mathrm{~min}{ }^{-1}$. Elution of 2,4-DCP was achieved with methanol-acetic acid 90:10 ( $v / v)$ $(10 \mathrm{~mL})$. The eluent was then purged with nitrogen to remove the solvent and $2 \mathrm{~mL}$ water was then added to the bottle before chemiluminescence determination with the LF-800.

Water samples were preconcentrated with the MISPE cartridge. Freshly collected water sample $(100 \mathrm{~mL})$ was filtered through a $0.45-\mu \mathrm{m}$ filter to remove suspended particles and acidified to $\mathrm{pH} 2.0$ with phosphoric acid. The water sample was passed through the cartridge at $2-3 \mathrm{~mL} \mathrm{~min}^{-1}$. The column was eluted with methanol-acetic acid 90:10 ( $v / v)$ $(10 \mathrm{~mL})$ to remove any 2.4-DCP. The eluent was then purged with nitrogen to remove the solvent and $2 \mathrm{~mL}$ water was then added to the bottle before chemiluminescence determination with the LF-800.

\section{Binding characteristic assays}

The binding properties of the MIP were studied by batch and dynamic methods as already reported [33].

In a typical rebinding experiment by the batch method, $2.5 \mathrm{mg}$ washed and dried MIP or NIP were added to $5 \mathrm{~mL}$ solutions of 2,4-DCP at different concentrations in pure water. The suspensions were then sealed and shaken for $20 \mathrm{~h}$ at room temperature to ensure equilibration. After centrifugation at $3500 \mathrm{rpm}$ for $10 \mathrm{~min}$, the concentration of free 2,4-DCP in the supernatant was detected by measuring the UV absorbance at $\lambda_{\max }=284 \mathrm{~nm}$. The amount of $2,4-$ DCP bound to the polymer was calculated by subtracting the concentration of free 2,4-DCP from the initial concentration. The data obtained were used for Scatchard analysis.

In the dynamic method, $4.0 \mathrm{mg}$ MIP or NIP were added to a solution of 2,4-DCP in pure water $\left(1.6 \times 10^{-4} \mathrm{~g} \mathrm{~mL}^{-1}\right.$, $30.0 \mathrm{~mL}$ ), the solution was shaken and the amount of $2,4-$ DCP in the solution was determined at different times by use of the UV-2401PC at $\lambda_{\max }=284 \mathrm{~nm}$.

For spectrophotometric analysis, $3.2 \mathrm{mg}$ 2,4-DCP was added to $30 \mathrm{~mL} \mathrm{CHCl}_{3}$ solution $\left(C_{0}=0.6544 \mathrm{mmol} \mathrm{L}^{-1}\right)$. 4 VP (molar ratio 1:1, 1:2, 1:4, and 1:8) was added and the solutions were shaken for $3 \mathrm{~h}$ and the amount of 2,4-DCP was determined by use of the UV-2401PC.

\section{Chemiluminescence determination of 2,4-DCP}

As shown in Fig. 1, the mobile phase was water and the volume of sample injected was $50 \mu \mathrm{L}$ in all instances (blanks, standards, and samples). Solutions of $\mathrm{KMnO}_{4}$ and luminol were delivered by a peristaltic pump at a flow rate (per tube) of $1.2 \mathrm{~mL} \mathrm{~min}^{-1}$, mixed in a mixing coil, and then merged and reacted with the solution from the MISPE. The emitted light was monitored by means of a photomultiplier tube (operated at $-800 \mathrm{~V}$ ). Quantitative determination was based on net CL intensity $\Delta I=I_{S}-I_{0}$, where $I_{\mathrm{S}}$ was the CL intensity of 2,4-DCP and $I_{0}$ was the intensity of the blank signal.

\section{Results and discussion}

\section{Polymer synthesis}

A large number of factors have effects on the molecular recognition properties of the synthesized polymer, such as the amount of the template molecule, the type and the amount of monomer, and the cross linking agent. According to reported work, the optimum ratio of the molar amounts of the template molecule, functional monomer, cross-linker, and initiator for the preparation of polymers is 1:4:20:1.12.

The solvent used for the polymerization was also of great importance - it may either enhance or destabilize the specific interactions which lie at the heart of the imprinting effect. Beside its function as a porogen to control polymer morphology, it governs the strength of non-covalent interaction. In general, the more polar the porogen, the greater the disruption of the non-covalent interactions and the weaker the resulting recognition effect. In order to optimize the binding strengths, the common used imprinting porogens are solvents of low dielectric constant, such as toluene, 


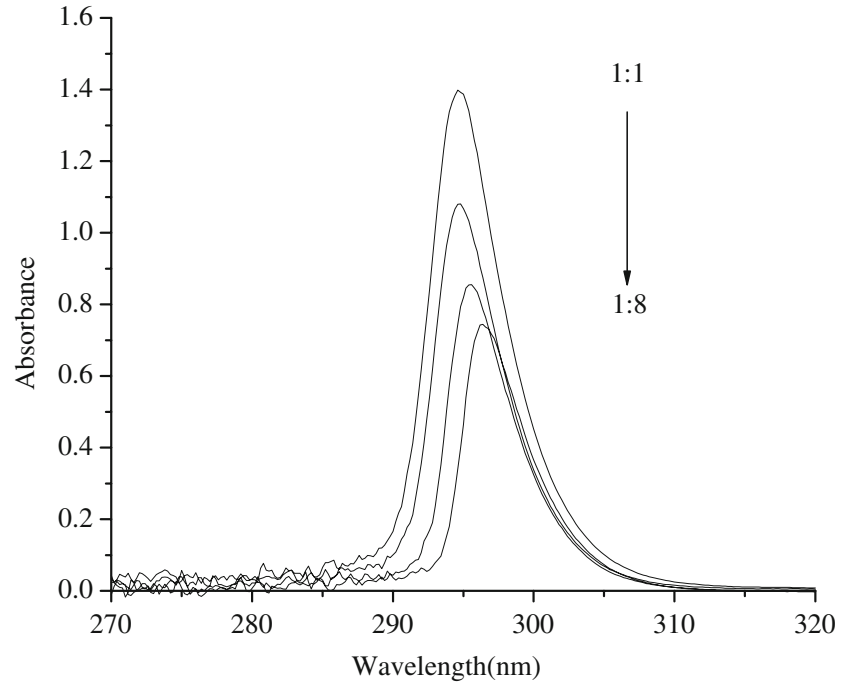

Fig. 2 Effect of different 4-VP content on the ultraviolet spectrum of 2,4-DCP in chloroform $\left(C_{0}=0.6544 \mathrm{mmol} \mathrm{L}^{-1}\right)$ (from top to bottom: $1: 1,1: 2,1: 4,1: 8)$

acetonitrile, and chloroform. In this work, chloroform was selected as the porogen.

For the template-to-monomer molecular ratio, different molecular ratios of 2,4-DCP-to-4-VP were selected by spectrophotometric analysis. Spectrophotometric analysis was carried out as described in the Experimental section. As seen in Fig. 2, as the amount of 4-VP was increased, the intensity of absorption by 2,4-DCP decreased. At the same time, the wavelength of maximum absorption had a red shift; the wavelengths were approximately 294.6, 294.8, 295.6, and 296.4, respectively. This indicated that the selfassembly structure was formed by interaction between 2, 4-DCP and 4-VP by hydrogen bonding and that the interaction gave rise to the three-dimensional geometry of the site during the later polymerization and contributed to the overall site quality.

\section{Study of absorption kinetics}

In order to examine the velocity of adsorption, the dynamic method was also carried out. As seen in Fig. 3a, adsorption of 2,4-DCP by the MIP was very fast in the first $2 \mathrm{~h}$ then the speed declined rapidly; after $6 \mathrm{~h}$, the MIP no longer adsorbed 2,4-DCP. This was possibly because at the beginning the template molecules were captured in the cavities at the surface of the MIP. After all the cavities at the surface were occupied, the template molecules had to be transported to the inside of the MIP which would take much more time. Similar experiments were carried out on the NIP. As seen in Fig. 3b, the NIP adsorb 2,4-DCP very rapidly in the first $30 \mathrm{~min}$ then the speed declined rapidly; after $1.5 \mathrm{~h}$, the NIP no longer adsorbed 2,4-DCP. The amount of absorbance of 2,4-DCP in the NIP was lower than that of 2,4-DCP in MIP. The difference between the two was the contribution of the cavities of the MIP.

Equilibrium rebinding experiments and Scatchard analysis

Binding assays were carried out in water solution instead of chloroform because the determination of 2,4-DCP was applied to water samples. The data obtained from the batch-type method with 2,4-DCP concentration from 10 to $400 \mathrm{mg} \mathrm{L}^{-1}$ were plotted according to the binding isotherm, which is shown in Fig. 4. The Scatchard analysis demonstrated that the equilibrium dissociation constant $K_{\mathrm{d}}$ and the maximum amount adsorbed $Q_{\max }$ were $389.11 \mathrm{mg} \mathrm{L}^{-1}$ and $4.56 \mathrm{mmol} \mathrm{g}^{-1}$, respectively, for the MIP and $1,626.01 \mathrm{mg} \mathrm{L}^{-1}$ and $1.32 \mathrm{mmol} \mathrm{g}^{-1}$ for the NIP. $K_{\mathrm{d}}$ is small and $Q_{\max }$ is large when the affinity between polymers and template molecules is strong. Therefore, the different values of $K_{\mathrm{d}}$ and $Q_{\max }$ for the MIP and NIP were because of the presence of specific cavities in the MIP.
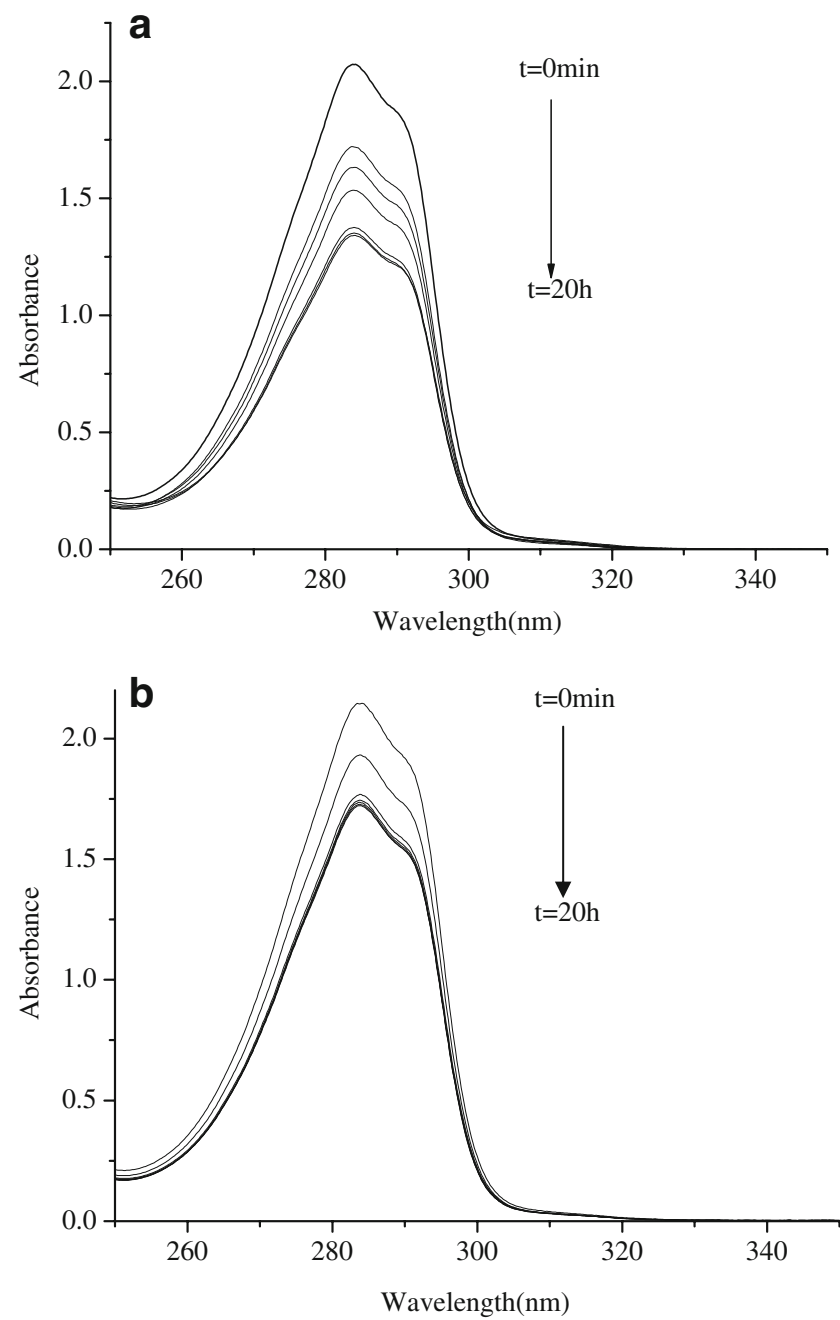

Fig. 3 Adsorption kinetics of the polymers (a MIP, b NIP) (from top to bottom: $\mathrm{t}=0 \mathrm{~min}, 10 \mathrm{~min}, 30 \mathrm{~min}, 1 \mathrm{~h}, 2 \mathrm{~h}, 6 \mathrm{~h}, 20 \mathrm{~h}$ ) 


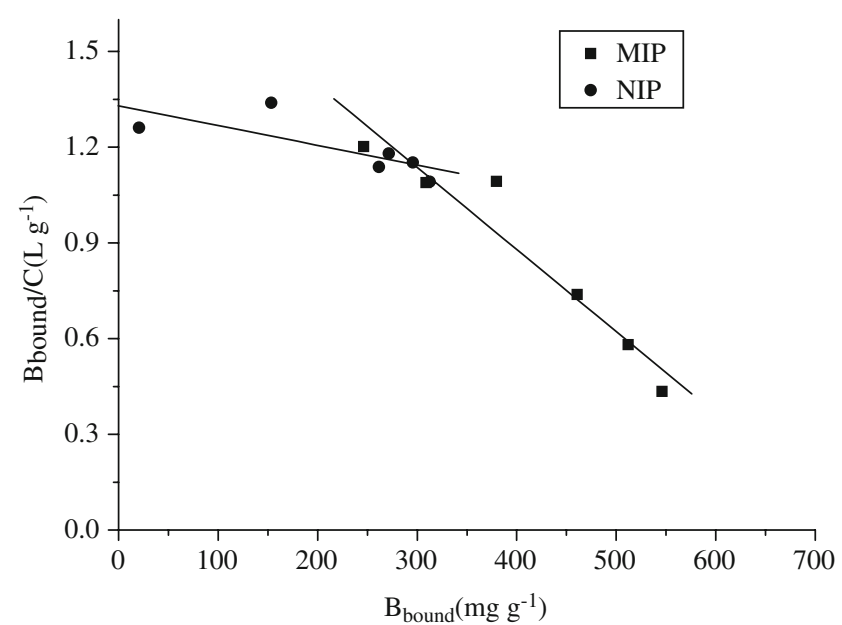

Fig. 4 Binding isotherm of 2,4-DCP-imprinted polymer

Binding selectivity of the polymers

In order to verify that the imprinted polymers were selective to 2,4-DCP, the binding selectivity of 2,4-DCP and some structurally related compounds on the polymers were investigated. These structurally related compounds $\left(2.5 \times 10^{-6} \mathrm{~g} \mathrm{~mL}^{-1}\right.$ pure water solution) were 4-chlorophenol (4-CP), 2,6-dichlorophenol (2,6-DCP), 2,4,6-trichlorophenol (2,4,6-TCP) and 2,4-dimethylphenol (2,4-DMP).

Figure 5 shows the selective properties of MIP and NIP. The molecularly imprinted polymers had high binding affinity for 2,4-DCP while the other compounds had less binding capacity. The non-molecularly imprinted polymers had least binding affinity for 2,4-DCP and the other compounds. 2,4-DMP had less binding affinity than 2,4-DCP, because $-\mathrm{CH}_{3}$ replaced the $-\mathrm{Cl}$, and $-\mathrm{CH}_{3}$ and $-\mathrm{Cl}$ have the different shape and spatial structure; 2,6-DCP had less binding affinity than 2,4-DCP, since the spatial group $-\mathrm{Cl}$ had changed. 4-CP and 2,4,6-TCP have more and less $-\mathrm{Cl}$, respectively, than 2,4-DCP; they had less affinity but still had some affinity. The imprinting factors were close to 1.3

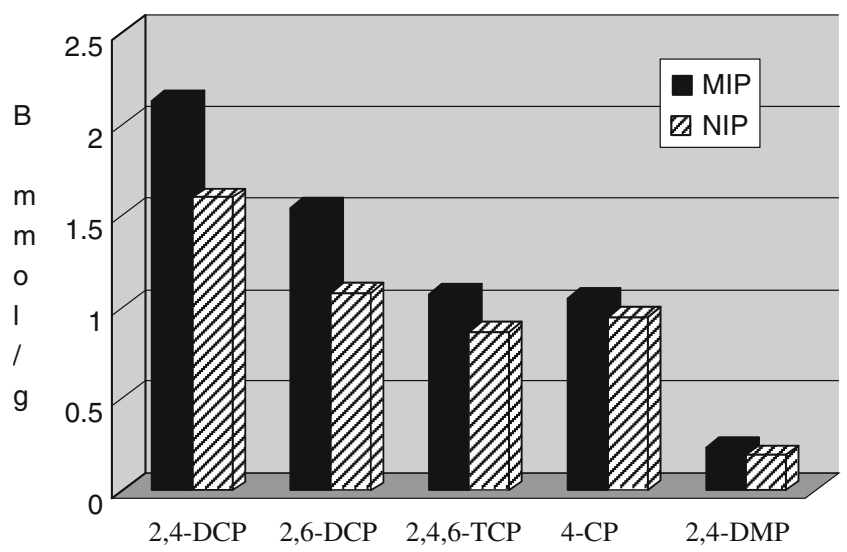

Fig. 5 Binding selectivity test of 2,4-DCP and structurally related compounds on the MIP and NIP for 2,4-DCP, 2,6-DCP, and 2,4,6-TCP and only 1.1 for 4$\mathrm{CP}$ and 2,4-DMP.

\section{Optimization of the CL system}

The reaction between potassium permanganate and luminol in the alkaline medium produced weak CL emission, strong $\mathrm{CL}$ emission was recorded when 2,4-DCP was injected into this mixed solution. The peak heights of CL emission were proportional to the concentration of 2,4-DCP. In order to achieve maximum relative CL intensity for all analytes, a batch experiment was carried out. Factors that probably influence the reaction, such as reagent concentration and reaction medium were investigated. In the optimum processes, $5.0 \times 10^{-6} \mathrm{~g} \mathrm{~mL}^{-1}$ standard solutions were employed for 2 , 4-DCP.

The effect of $\mathrm{KMnO}_{4}$ concentration on the CL intensity was studied in the range $1.0 \times 10^{-6}$ to $2.5 \times 10^{-5} \mathrm{~mol} \mathrm{~L}^{-1}$.
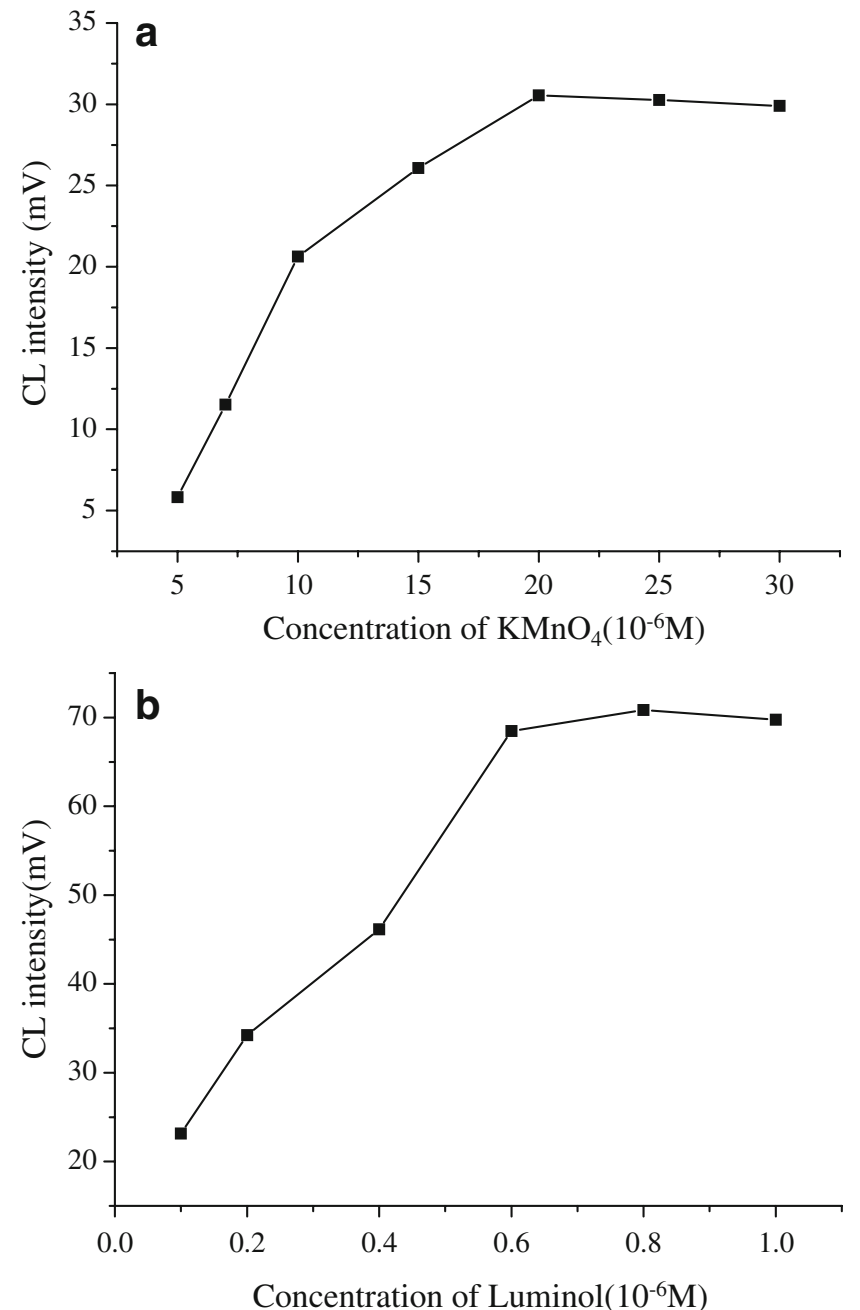

Fig. 6 Effect of $\mathrm{KMnO}_{4}$ and luminol concentrations on $\mathrm{CL}$ signal. a $C_{l u \text { minol }}=8.0 \times 10^{-7} \mathrm{molL}^{-1}, C_{\mathrm{NaOH}}=1 \mathrm{mmol} \mathrm{L} \mathrm{L}^{-1}$, flow rate $1.2 \mathrm{~mL} \mathrm{~min}^{-1} ; \mathbf{b} C_{\mathrm{KMnO} 4}=2.0 \times 10^{-5} \mathrm{molL}^{-1}, C_{\mathrm{NaOH}}=1 \mathrm{mmol} \mathrm{L}^{-1}$, flow rate $1.2 \mathrm{~mL} \mathrm{~min}^{-1}$ 
Table 1 Determination of 2,4-DCP and other phenols (spiked water samples, $n=3$ )

\begin{tabular}{|c|c|c|c|c|c|c|}
\hline & & 2,4-DCP & 2,6-DCP & 2,4,6-ТCP & 4-CP & 2,4-DMP \\
\hline \multirow[t]{2}{*}{ MIP (tap water) } & Recovery (\%) & 97.5 & 77.5 & 75.8 & 47.5 & 52.6 \\
\hline & $\operatorname{RSD}(\%)$ & 5.0 & 8.3 & 8.4 & 10.5 & 10.7 \\
\hline \multirow[t]{2}{*}{ MIP (river water) } & Recovery (\%) & 71.7 & 63.2 & 61.8 & 48.0 & 43.6 \\
\hline & RSD (\%) & 3.1 & 10.0 & 12.1 & 6.2 & 10.4 \\
\hline \multirow[t]{2}{*}{ NIP (tap water) } & Recovery (\%) & 36.0 & 40.3 & 37.5 & 33.3 & 30.0 \\
\hline & $\operatorname{RSD}(\%)$ & 8.3 & 7.1 & 8.0 & 10.0 & 8.3 \\
\hline \multirow[t]{2}{*}{ NIP (river water) } & Recovery (\%) & 39.3 & 43.3 & 35.4 & 27.2 & 23.0 \\
\hline & RSD (\%) & 9.1 & 8.8 & 9.0 & 10.3 & 8.7 \\
\hline
\end{tabular}

As shown in Fig. 6a, the CL intensity increased with increasing $\mathrm{KMnO}_{4}$ concentration up to $2.0 \times 10^{-5} \mathrm{~mol} \mathrm{~L}^{-1}$ and then gradually decreased with continuously increasing concentration. The decrease in the signal at higher concentration of $\mathrm{KMnO}_{4}$ was owing to the adsorption of light emission by the intense color of the permanganate solution, thus the optimum concentration of $\mathrm{KMnO}_{4}$ was $2.0 \times 10^{-5} \mathrm{~mol} \mathrm{~L}^{-1}$.

The effect of luminol concentration on the CL intensity was examined in the range $1.0 \times 10^{-7}$ to $1.0 \times 10^{-6} \mathrm{~mol} \mathrm{~L}^{-1}$. As shown in Fig. 6b, the CL intensity increased with the increasing luminol concentration up to $8.0 \times 10^{-7} \mathrm{~mol} \mathrm{~L}^{-1}$ and then decreased gradually with continuously increasing concentration. So, the optimum concentration of luminol was $8.0 \times 10^{-7} \mathrm{~mol} \mathrm{~L}^{-1}$.

The effect of sodium hydroxide concentration on the CL intensity was examined in the range $0.2-4.0 \mathrm{mmol} \mathrm{L}^{-1}$. The $\mathrm{CL}$ reaction had the maximum signal-to-blank ratio when $1.0 \mathrm{mmol} \mathrm{L}^{-1}$ sodium hydroxide concentration was used. Therefore, $1.0 \mathrm{mmol} \mathrm{L}^{-1}$ sodium hydroxide concentration was chosen.

The influence of the flow rate for each solution was examined in the range $0.3-1.7 \mathrm{~mL} \mathrm{~min}^{-1}$. It was found that the maximum signal-to-blank ratio was achieved when the flow rate was $0.9-1.4 \mathrm{~mL} \mathrm{~min}^{-1}$. So, $1.2 \mathrm{~mL} \mathrm{~min}^{-1}$ was selected.

\section{Analytical performance}

Under the optimum experimental conditions described above, the calibration graph of the CL intensity versus 2,4-DCP concentration was linear from $1 \times 10^{-7}$ to $2 \times$ $10^{-5} \mathrm{~g} \mathrm{~mL}^{-1}$, LOD (limit of detection $S / N=3$ ) $=1.8 \times$ $10^{-8} \mathrm{~g} \mathrm{~mL}^{-1}$. The regression equation was $\Delta I=11.6268 \mathrm{C}+$ 4.0353 (where $C$ is the 2,4-DCP concentration $\left(\mathrm{g} \mathrm{mL}^{-1}\right)$ ) with a correlation coefficient of $0.9964(n=8)$. The reproducibility of the system was measured for $1.4 \times 10^{-6} \mathrm{~g} \mathrm{~mL}^{-1} 2,4-\mathrm{DCP}$ and the calculated relative standard deviation (RSD) was $3.0 \%(n=11)$. This demonstrated that the MISPE and CL system was sufficiently sensitive for determination of traces of 2,4-DCP.
Interference studies

In order to assess the possible analytical application of the proposed CL system to water samples, the effect of some common chemicals possibly found in water was studied by adding the chemicals to solutions containing $5.0 \times$ $10^{-6} \mathrm{~g} \mathrm{~mL}^{-1} 2,4-\mathrm{DCP}$ standard. The tolerable concentration ratios with respect to $5.0 \times 10^{-6} \mathrm{~g} \mathrm{~mL}^{-1} 2,4-\mathrm{DCP}$ standard solution for interference at less than $5 \%$ level were over 1000 for $\mathrm{K}^{+}, \mathrm{Na}^{+}, \mathrm{Cl}^{-}, \mathrm{SO}_{4}^{2-}, \mathrm{NO}_{3}^{-}$and $\mathrm{NO}_{2}^{-}$, over 100 for $\mathrm{Cr}^{3+}$, over 50 for $\mathrm{ClO}_{4}^{-}, \mathrm{NH}_{4}^{+}, \mathrm{Mg}^{2+}$, and $\mathrm{Ca}^{2+}$, and over 5 for $\mathrm{PO}_{4}^{3-}$. Further study showed that other organic compounds, for example phenol and benzene, did not interfere within the normal concentrations in water samples.

\section{Method validation and application}

Following these procedures, the proposed method was used to determine 2,4-DCP and other phenolic compounds in real samples, i.e. both spiked and non-spiked water samples (tap water and river water). Table 1 shows the results obtained. Surface water was collected from Qinghe River (Beijing, China) and preconcentrated by MISPE as described in the Experimental section. None of the 2,4-DCP and other phenolic compounds could be determined in nonspiked water, maybe because there was little 2,4-DCP in the Qinghe river in Beijing. For the spiked water sample $(0.2 \times$ $10^{-6} \mathrm{~g} \mathrm{~mL}^{-1}$ ), the concentration factor was 50 . The river matrix did not significantly interfere with detection.

\section{Conclusions}

The 2,4-DCP-imprinted polymer was prepared by bulk polymerization using 4-VP and EGDMA as the monomer and cross-linker, respectively. The obtained polymer had good selectivity and enrichment efficiency. Thus, a method was successfully developed by using the 4-VP-co-EGDMA polymer as the MISPE for enriching 2,4-DCP in river water. Based on the sensitizing effect of 2,4-DCP on the CL 
reaction of potassium permanganate and luminol in alkaline media, a combination of MISPE with a novel CL-postcolumn detection was established for analysis of 2,4-DCP. The developed MISPE-CL method was used to determine the 2,4-DCP content of river water directly and the recovery results validated the method.

Acknowledgements This work was supported by the National Natural Science Foundation of China (Grant Nos. 20437020 and 20621703) and the Major Research Program of the Chinese Academy of Sciences (KZCX3-SW-432).

\section{References}

1. Gary W, Gary L, James T (1982) Arch Environ Contam Toxicol 11:73-82

2. Li XD, Yue YD, Hua R, Huang HS, Yu L, Liao M, Li XH (2002) Agro-Environ Prot 21:156-158

3. Tsuji N, Hirooka T, Nagase H, Hirata K, Miyamoto K (2003) Biotechnol Lett 25:241-244

4. Contreras S, Rodríguez M, Al Momani F, Sans C, Esplugas S (2003) Water Res 37:3164-3171

5. Swaminathan G, Ramanujam TK (1999) Bioprocess Eng 21: 169-173

6. Oliveira R, Manuel FA, Santos L, Madeira LM (2006) Ind Eng Chem Res 45:1266-1276

7. Gao JJ, Liu LH, Liu XR, Zhou HD, Huang SB, Wang ZJ (2007) Chemosphere, in press

8. Wang HT, Zhu K, Wei X, Zhang L, Yang JT, Ma J (2003) J Lanzhou Railway University 22:31-33

9. Ureta-Zañartu MS, Bustos P, Berríos C, Diez MC, Mora ML, Gutiérrez C (2002) Electrochim Acta 47:2399-2406

10. Hahn D, Cozzolino A, Piccolo A, Armenante PM (2007) Ecotoxicol Environ Saf 66:335-342

11. Laurent F, Debrauwer L, Pascal-Lorber S (2006) Pest Manag Sci 62:558-564
12. Gallizia I, McClean S, Banat IM (2003) J Chem Technol Biotechnol 78:959-963

13. Drzewicz P, Pahta P, Gluszewski W, Trojanowicz M (1999) J Radioanal Nucl Chem 242:601-609

14. Zhang W, Danielson ND (2003) Anal Chim Acta 493:167-177

15. Tsukagoshi K, Kameda T, Yamamoto M, Nakajima R (2002) J Chromatogr A 978:213-220

16. Hindson BJ, Barnett NW (2001) Anal Chim Acta 445:1-19

17. Yang CY, Zhang ZJ, Chen SM, Yang F (2007) Microchim Acta 159:299-304

18. Xiong Y, Zhou HJ, Zhang ZJ, He DY, He C (2006) Analyst 31:829-834

19. Caro E, Masque N, Marce RM, Borrulla F, Cormack PAG, Sherrington DC (2002) J Chromatogr A 963:169-178

20. Muldoon MT, Stanker LH (1997) Anal Chem 69:803-808

21. Andersson LI, Paprica A, Arvidsson T (1997) Chromatographia 46:57-62

22. Urraca JL, Moreno-Bondi MC, Hall AJ, Sellergren B (2007) Anal Chem 79:695-701

23. Caro E, Marce RM, Cormack Peter AG, Sherrington DC, Borrull F (2003) J Chromatogr A 995:233-238

24. Masque N, Marce RM, Borrull F, Cormack PAG, Sherrington DC (2000) Anal Chem 72:4122-4126

25. Garcia R, Pinel C, Madic C, Lemaire M (1998) Tetrahedron Lett 39:8651-8654

26. Möller K, Nilsson U, Crescenzi C (2001) J Chromatogr A 938: $121-130$

27. Tsuru N, Kikuchi M, Kawaguchi H, Shiratori S (2006) Thin Solid Films 449:380-385

28. He DY, Zhang ZJ, Zhou HJ, Huang Y (2006) Talanta 69:12151220

29. Lavignac N, Allender CJ, Brain KR (2004) Anal Chim Acta 510:139-145

30. Piletsky SA, Piletska EV, Bossi A, Karim K, Lowe P, Turner APF (2001) Biosens Bioelectron 16:701-707

31. Huang JT, Zheng SH, Zhang JQ (2004) Polymer 45:4349-4354

32. Southard GE, Van Houten KA, Murray GM (2007) Macromolecules 40:1395-1400

33. Xiong Y, Zhou HJ, Zhang ZJ, He DY, He C (2007) Spectrochim Acta A 66:341-346 